Electronic Supplementary Information (ESI)

\title{
Site-specific crosslinking of the p19 viral suppressor of RNA silencing protein and its RNA targets using an expanded genetic code
}

\author{
Noreen Ahmed ${ }^{1}$, Dana V. Foss ${ }^{2}$, Megan H. Powdrill ${ }^{1}$, and John Paul Pezacki ${ }^{1,2, *}$ \\ ${ }^{1}$ Department of Biochemistry, Microbiology and Immunology University of Ottawa, Ottawa, \\ Ontario, K1N 6N5 \\ ${ }^{2}$ Department of Chemistry and Biomolecular Sciences, University of Ottawa, Ottawa, Ontario, \\ K1N 6N5 \\ * Corresponding author; John.Pezacki@uottawa.ca
}

Supplemental Figures:

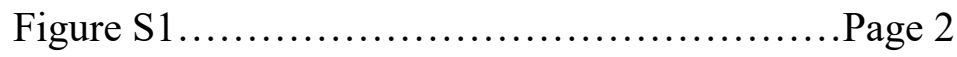

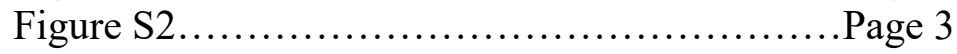


(A)

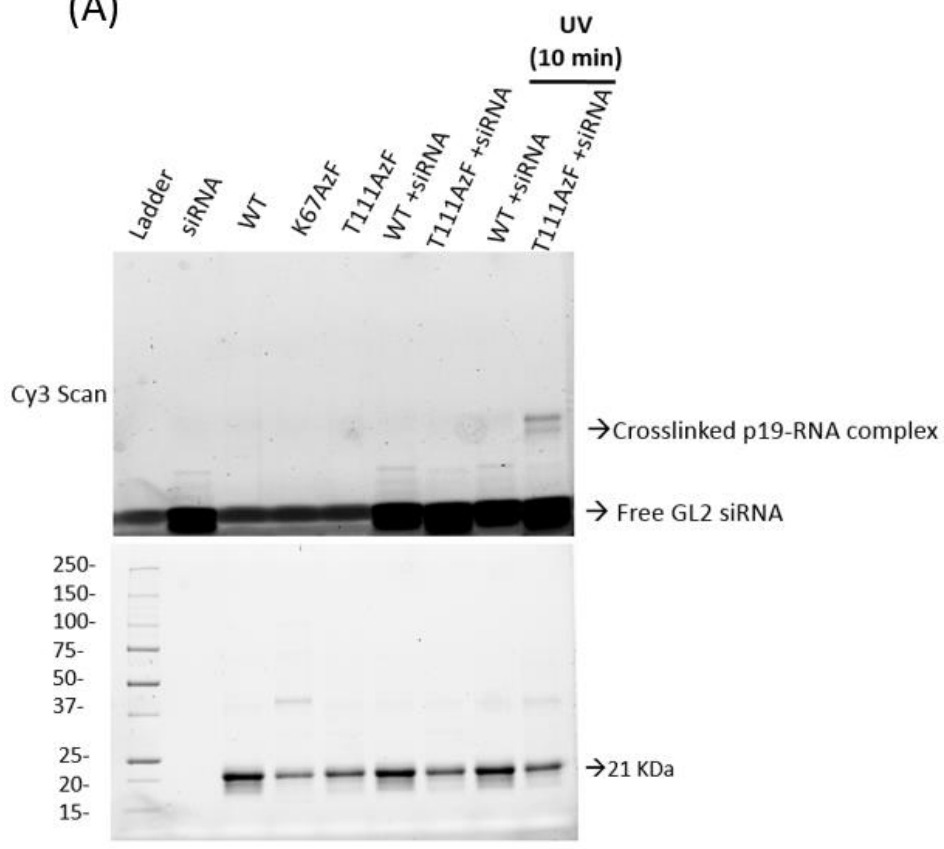

(B)

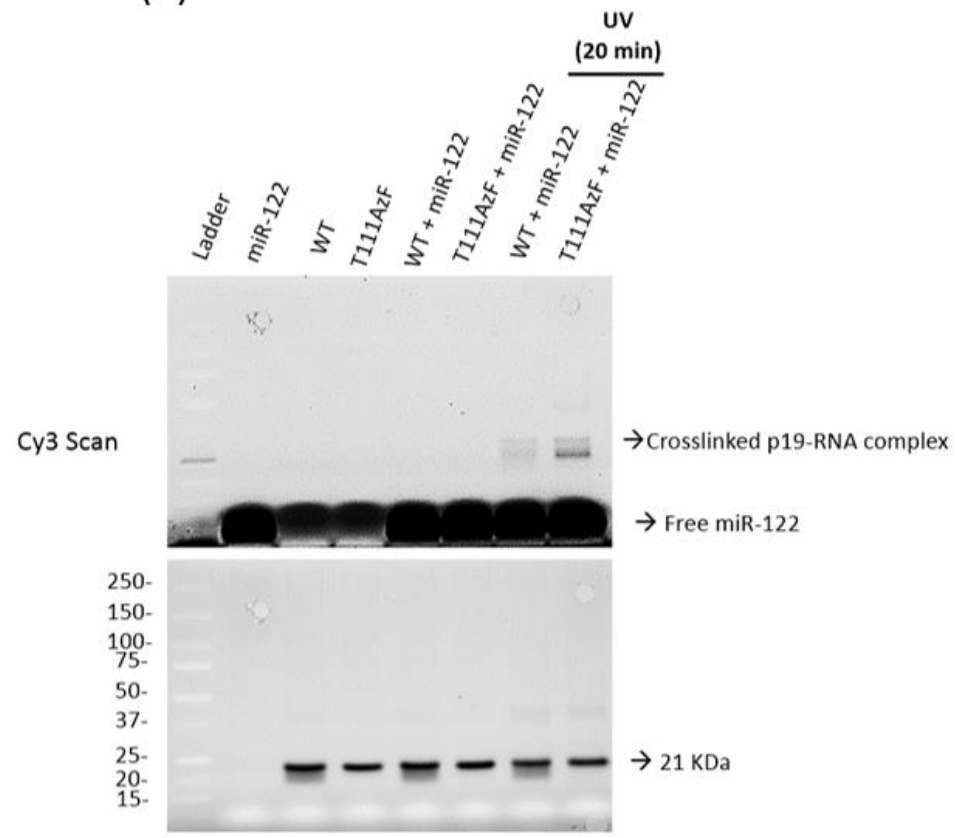

Figure S1: Crosslinking of p19 and small RNAs. A) Gel of p19 WT and T111AzF after UV exposure for 10 minutes at $320 \mathrm{~nm}$. Top gel is the Cy3 Scan, confirming crosslinking of GL2 siRNA to T111AzF, while unbound Cy3 labelled GL2 siRNA appears at the bottom of the gel. Bottom gel is the loading control to confirm equal loading (TGX-Stain Free). B) Gel of p19 T111AzF after UV exposure for 20 minutes at $320 \mathrm{~nm}$. Top gel is the Cy3 Scan, confirming photo-crosslinking of miR-122 to T111AzF, while unbound Cy3 labelled miR-122 appears at the bottom of the gel. Bottom gel is the loading control to confirm equal loading (TGX-Stain Free). 

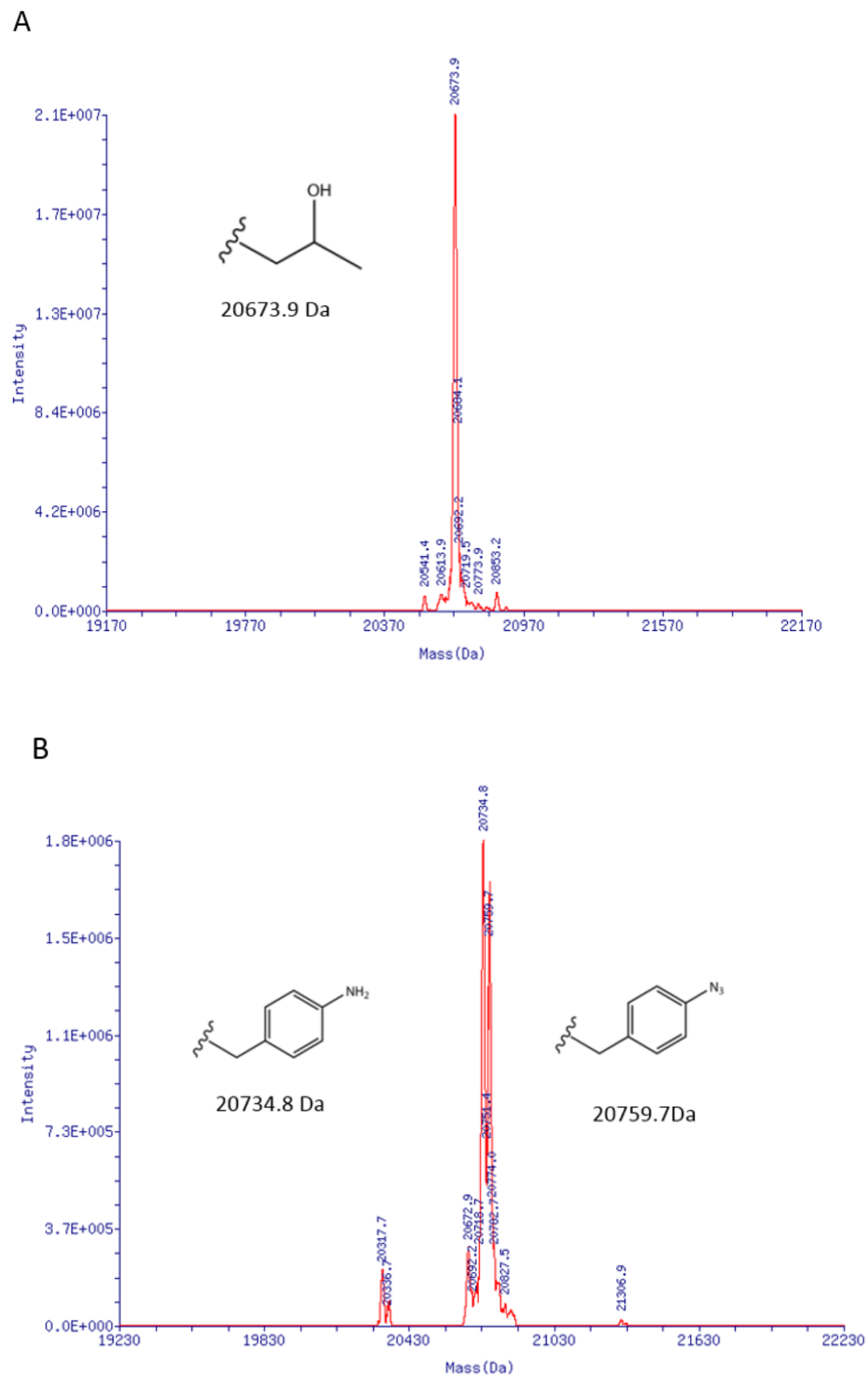

Figure S2: Mass spectrum to confirm incorporation of Azidophenylalanine site specifically. A) Mass spectra showing major peak at 20673.9 Da representing p19 WT. B) Mass spectra for the mutant $\mathrm{T} 111 \mathrm{AzF}$ representing the incorporation of $\mathrm{AzF}$ in a site specific manner, showing two species due to reduction of azide during the purification and preparation of protein for the MS experiment. 